\title{
The neural system for the inhibition of startle
}

\author{
DONALD S. LEITNER, ALICE S. POWERS, and HOWARD S. HOFFMAN \\ Graduate School of Arts and Sciences, Bryn Mawr College, Bryn Mawr, Pennsylvania 19010
}

\begin{abstract}
In the rat, lesion of the lateral tegmentum but not of the raphe eliminated inhibition of acoustic startle by prior acoustic and visual stimuli with lead times of $50 \mathrm{msec}$. Since lesion of the lateral tegmentum did not interfere with latency reduction (when the same prior stimuli had lead times of $4 \mathrm{msec}$ ), it is concluded that lesion of the lateral tegmentum interferes with an inhibitory system while leaving sensory processing intact.
\end{abstract}

In the rat, as in a variety of other species (including man), a sensory event that occurs just prior to an intense startle-eliciting stimulus can modify either the latency or the amplitude of the startle response, depending on the lead time. With a lead time of approximately $50 \mathrm{msec}$, the amplitude of the startle response is considerably reduced, but response latency is either unaffected or somewhat increased. With a lead time of only $4 \mathrm{msec}$, the latency of the response is reduced, but response amplitude is usually unaffected. In general, these reflex modification effects occur regardless of the modality through which either the reflex-modifying or the startleeliciting signals are delivered. Both amplitude and latency reduction of startle are obtained when either a light flash or a brief noise is presented at an appropriate interval prior to an intense startle-eliciting acoustic stimulus.

Recent analysis of these effects across a variety of experiments has led to the conclusion that the startle reflex is probably elaborated in a specific neural system and that latency reduction by a prior signal with a short lead time occurs because the prior signal somehow facilitates (i.e., primes) this system. This analysis also implied that startle inhibition by an appropriate prior signal (i.e., a signal with a long lead time) is probably mediated by a separate system that impinges on the system in which startle is elaborated (Hoffman \& Ison, in press). We report here that lesions of the lateral midbrain tegmentum in the rat eliminated the startle inhibition effect implying that this region may contain a neural system in which the inhibition phenomenon is mediated.

Many attempts to localize such a system have been made in the past, but until now all were unsuccessful. Early efforts to abolish inhibition of the startle reflex by brain lesions concentrated on cortical and limbic structures in the forebrain, which had been implicated in behavioral inhibition (e.g., McCleary, 1961). Kemble

This research was supported by Grant HD 10511, directed by Howard S. Hoffman. The authors wish to thank Tracy Thompson and Bruce Goldberg for their assistance. Reconstructions of the lesions, as well as reprints, can be obtained from Howard S. Hoffman, Department of Psychology, Dalton Hall, Bryn Mawr College, Bryn Mawr, Pennsylvania 19010. and Ison (1971) found no change in reflex inhibition after lesions of septal, amygdaloid, and hippocampal areas. Groves, Boyle, Welker, and Miller (1974) failed to find an effect on startle inhibition following lesions of the hippocampus, parietal cortex, and frontal cortex. Hammond (1974) also found no effect of frontal lesions on inhibition of the startle reflex. In short, all the findings on the effects of forebrain lesions on startle inhibition have been negative.

Davis and Gendelman (1977) showed that transection of the brain between the thalamus and midbrain did not abolish either startle or its inhibition by prestimulation. It was clear that the locus of both effects must be caudal to the mesencephalic-diencephalic junction. One attempt had been made to localize the effect in reticular structures of the hindbrain. Hammond (1973) made lesions in the pontine and medullary reticular formation and found that, although startle was reduced after lesions of nucleus reticularis pontis caudalis (see below), inhibition was not affected.

Stitt, Hoffman, Marsh, and Schwartz (1976) suggested that the cerebellum might be the locus of the inhibitory effect. However, unpublished observations from our laboratory and that of Ison (Note 1) have failed to find any effect of cerebellar lesions on the startle response or its inhibition by prestimulation. Thus, numerous investigations sought the locus of startle inhibition and failed to find it.

We were encouraged to renew this search because recent investigations (Gendelman \& Davis, 1979) have provided evidence that nucleus reticularis pontis caudalis is almost certainly the locus of the final elaboration of startle. Electrical stimulation of a specific site in this area produces a full-blown startle reaction, and small lesions at the site of the electrodes abolish the startle response to intense acoustic signals, even though there is no obvious impairment of either the rat's hearing or its motor function.

In view of these findings, it seemed reasonable to assume that any site that might be the locus of reflex inhibition would have to (1) receive input from each of several sensory modalities and (2) project on nucleus reticularis pontis caudalis. Examination of the literature revealed that cells in nucleus cuneiformis of the lateral 
tegmentum project on pontis caudalis (Edwards, 1975; Gallager \& Pert, 1978) and that this region probably receives input from several modalities (Bell, Sierra, Buendia, \& Segundo, 1964). The raphé nucleus also meets these criteria (Anderson, Basbaum, \& Fields, 1977; Gallager \& Pert, 1978). In the work described here, we tested for the effects of latency and amplitude reducing prior signals on rats with lesions in lateral tegmentum and in raphé and compared these effects with those engendered in unoperated animals.

\section{METHOD}

\section{Subjects}

Seven experimentally naive male 90-day-old albino rats from West Jersey Biological Supply were tested. Two of the animals received lesions of lateral tegmentum; two others received lesions of the raphé nucleus.

\section{Apparatus}

The equipment for producing and assessing startle reactions has been fully described elsewhere (Schwartz, Hoffman, Stitt, \& Marsh, 1976). Briefly, it consisted of units to produce controlled acoustic and visual signals and a specialized chamber to measure the amplitude and latency of the abrupt crouch-like movement that characterizes overt startle.

\section{Procedure}

Bilateral lesions were produced electrolytically by passing a current of $1 \mathrm{~mA}$ through electrodes at the predetermined sites. Current duration was $10 \mathrm{sec}$ for the raphe subjects and $15 \mathrm{sec}$ for the lateral tegmentum subjects. For all subjects, including the unoperated controls, testing began 14 days after the lesions had been completed. In general, the procedures were similar to those employed by Hoffman and Wible (1970) and by Schwartz et al. (1976). In a given test, a subject was exposed to a startleeliciting burst of noise (intensity $120 \mathrm{~dB}$ SPL, duration $20 \mathrm{msec}$, rise-fall time $<1 \mathrm{msec}$ ) every $20 \mathrm{sec}$ for a total of 100 trials. On 50 randomly selected trials, the startle-eliciting signal was preceded by a reflex-modifying sensory event. In a given test, this event was either a $20-\mathrm{msec} 80-\mathrm{dB}$ pulse of noise (e.g., an acoustic prepulse) or the flash of light produced by discharging a photoflash unit (e.g., a visual prepulse).

Each subject received four tests spread over a 3-week period. Two of the tests incorporated amplitude reduction paradigms in which the onset of the prepulse occurred $50 \mathrm{msec}$ prior to the onset of the startle-eliciting signal. The other two tests incorporated latency reduction paradigms in which prepulse onset occurred $4 \mathrm{msec}$ prior to the onset of the startle-eliciting signal. In summary, each subject was tested for inhibition by an acoustic and a visual prepulse and was also tested for latency reduction by these same prepulses. After completion of testing, the rats were deeply anesthetized and sacrificed by transcardial perfusion with saline followed by Heidenhain's solution. The brains were sectioned and stained, and the lesions were reconstructed on plates from Palkovits and Jacobowitz (1974).

\section{RESULTS}

In both animals with lesions of the lateral tegmentum, two structures were severely damaged bilaterally: the posterior part of the nucleus cuneiformis, including Cell Group A8 of Dahlström and Fuxe (1964), and the nucleus cuneiformis. In Subject 84, there was more bilateral damage to nucleus cuneiformis than in Subject 65. In addition to the damage described above,
Subject 65 had slight bilateral damage to nucleus reticularis pontis oralis.

The lesions of the raphe damaged the nucleus raphé pontis in both animals. The lesion in Subject 75 was more extensive than in Subject 74. Both animals had additional damage to the trapezoid body and medial lemniscus ventral to the raphé.

The left side of Table 1 shows the mean amplitude of startle reaction when the startle-eliciting signal was presented alone (at the left in each box) or was preceded by either an acoustic or a visual prepulse at a lead time that was appropriate to reduce response amplitude (at the right in each box). The right side of Table 1 shows the mean latency of startle reaction when the startle-eliciting stimulus was presented alone (at the left in each box) or was preceded by either an acoustic or visual prepulse at a lead time that was appropriate to reduce the latency of the response (at the right in each box).

The left side of Table 1 reveals first that there are relatively large but reasonably consistent individual differences in the amplitudes of response to the startle stimulus presented alone. In general, however, the response amplitudes of operated subjects are within the range of variation exhibited by the unoperated animals. Second, with the exception of subjects with lateral tegmental lesions, all animals exhibited large (and statistically reliable) reductions in response amplitude when the startle-eliciting signal was preceded by either an acoustic or a visual prepulse with an appropriately long lead time [in each case, $t(98)>1.985, \mathrm{p}<.05$ ] Since in more than 10 years of testing we have not previously encountered rats that startle well but show no inhibition, we are compelled to conclude that lesions of the lateral tegmentum have somehow interfered with the inhibition process.

Table 1

Differential Effects of Lesions on the Modification of Startle by Sensory Event that Precedes the Startle-Eliciting Signal

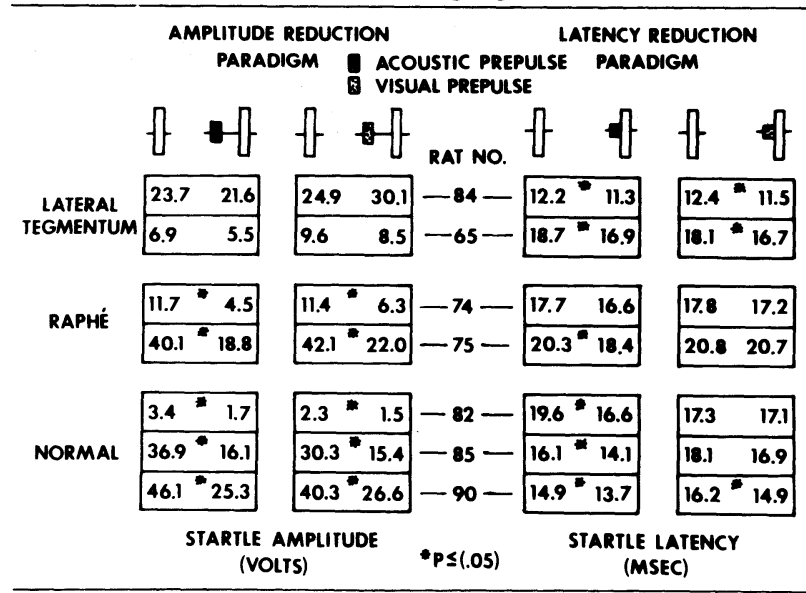

Note-The several stimulus configurations are represented schematically at the head of each column. Each entry is the mean startle amplitude or latency across 50 trials. 
The data at the right in Table 1 provide additional support for this conclusion. As was the case for response amplitude, there are large, but reasonably consistent, individual differences in the latency of the response to the startle stimulus presented alone. This time, however, the latency of one of the animals with a lesion in the lateral tegmentum (Rat 84) is shorter than that of any of the other animals. This observation is consistent with the proposition that lesion of the lateral tegmentum does not interfere with startle per se, and it suggests that this lesion may even have augmented the reaction.

In general, the presentation of either an acoustic or a visual prepulse with an appropriately short lead time tended to shorten response latency, but the effect was relatively small and for some animals was not statistically significant. Importantly, however, the latency reductions afforded by both acoustic and visual prepulses were statistically significant for the two animals that suffered lesions of lateral tegmentum. For these animals the same acoustic and visual signals that failed to generate reliable inhibition when presented in an amplitude-reduction paradigm produced a reliable (albeit small) reduction in response latency when presented in a latency-reduction paradigm. This is not what would have been expected if the lesions had reduced the sensory impact of the signals that served as prepulses. It implies that lesions of the lateral tegmentum disrupt a neural system in which the inhibition of startle is instigated. It is obvious that much more work will be needed before the details of such a system will be elaborated. In the meantime, the findings reported here provide encouragement for efforts in this direction.

\section{REFERENCE NOTE}

1. Ison, J. R. Personal communication, February 1979.

\section{REFERENCES}

Anderson, S. D., Basbaum, A. I., \& Fields, H. S. Response of medullary raphé neurons to peripheral stimulation and to systemic opiates. Brain Research, 1977, 123, 363-368.

Bell, C., Sierra, G., Buendia, N., \& Segundo, J. P. Sensory properties of neurons in the mesencephalic reticular formation. Journal of Neurophysiology, 1964, 27, 961-987.

Dahlström, A., \& FuXE, K. Evidence for the existence of monamine containing neurons in the central nervous system. I. Demonstration of monamines in the cell bodies of brain stem neurons. Acta Physiologica Scandinavica, 1964, 62, 1-55.

Davis, M., \& Gendelman, P. M. Plasticity of the acoustic startle response in the acutely decerebrate rat. Journal of Comparative and Physiological Psychology, 1977, 91, 549-563.

EDWARDS, S. B. Autoradiographic studies of the projections of the midbrain reticular formation: Descending projections of nucleus cuneiformis. Journal of Comparative Neurology, 1975, 161, 341-358.

Gallager, D. W., \& Pert, A. Afferents to brain stem nuclei (brain stem raphé, nucleus reticularis pontis caudalis, and nucleus gigantocellularis) in the rat as demonstrated by microiontophoretically applied horseradish peroxidase. Brain Research, 1978, 144, 257-275.

Gendelman, D. S., \& Davis, M. The primary acoustic startle circuit. Society for Neuroscience Abstracts, 1979, 5, 494.

Groves, P., Boyle, R., Welker, R., \& Miller, S. On the mechanism of prepulse inhibition. Physiology \& Behavior, 1974, 12, 367-375.

Hammond, G. R. Lesions of pontine and medullary reticular formation and prestimulus inhibition of the acoustic startle reaction in rats. Physiology \& Behavior, 1973, 10, 239-243.

Hammond, G. R. Frontal cortical lesions and prestimulus inhibition of the rat's acoustic startle reaction. Physiological Psychology, 1974, 2, 151-156.

Hoffman, H. S., \& Ison, J. R. Reflex modification in the domain of startle. I. Some empirical findings and their implications for how the nervous system processes sensory input. Psychological Review, in press.

Hoffman, H. S., \& Wible, B. L. Role of weak signals in acoustic startle. Journal of the Acoustical Society of America, 1970, 47, 489-497.

Kemble, E. D., \& Ison, J. R. Limbic lesions and the inhibition of startle reactions in the rat by conditions of preliminary stimulation. Physiology \& Behavior, 1971, 7, 925-928.

MCCle ARY, R. A. Response specificity in the behavioral effects of limbic system lesions in the cat. Journal of Comparative and Physiological Psychology, 1961, 54, 605-613.

Palkovits, M., \& Jacobowitz, D. M. Topographic atlas of catecholamine and acetylcholinesterase-containing neurons in the rat brain. II. Hindbrain (mesencephalon, rhombencephalon). Journal of Comparative Neurology, 1974, 157, 29-41.

Schwartz, G. M., Hoffman, H. S., Stitt, C. L., \& Marsh, R. R. Modification of the rat's acoustic startle response by antecedent visual stimulation. Journal of Experimental Psychology: Animal Behavior Processes, 1976, 2, 28-37.

Stitt, C. L., Hoffman, H. S., Marsh, R. R., \& Schwartz, G. M. Modification of the pigeon's visual startle reaction by the sensory environment. Journal of Comparative and Physiological Psychology, 1976, 90, 601-619.

(Received for publication September 21, 1979.) 